두 I픈 소

Jurnal Gentiaras Manajemen dan Akuntasi

Laman Jurnal: jurnal.gentiaras.ac.id/index.php/Gema/index

ISSN : 2086-9592 (p) , 2721-5490 (e)

\title{
Gaya Hidup, Orientasi Pilihan Strategi dan Pengambilan Keputusan Usaha pada UMKM di Kota Palembang
}

\author{
Anastasia Sri Sukistini, Antonius Singgih Setiawan*, Agustinus Widyartono \\ Universitas Katolik Musi Charitas, Sumatera Selatan \\ *email: singgih@ukmc.ac.id
}

\begin{tabular}{|c|c|}
\hline ARTICLE INFO & $A B S T R A C T$ \\
\hline $\begin{array}{l}\text { Artikel History: } \\
\text { Received: June 9, } 2021 \\
\text { Revised:July 28, } 2021 \\
\text { Published: July 31, } 2021\end{array}$ & \multirow[t]{2}{*}{$\begin{array}{l}\text { This study aims to prove the effect of lifestyle, strategy choice orientation on } \\
\text { business decision making. This study uses primary data through a survey of culinary } \\
\text { entrepreneurs in Palembang. The questionnaire data used in this study were } 92 \\
(61.3 \%) \text {. Analysis of Structural Equation Modeling (SEM) Partial Least Squares } \\
\text { (PLS) using Warp PLS software version } 5.0 \text { to examine the research. The results of } \\
\text { the study show that the lifestyle and strategy choice orientation affects business } \\
\text { decision-making. }\end{array}$} \\
\hline 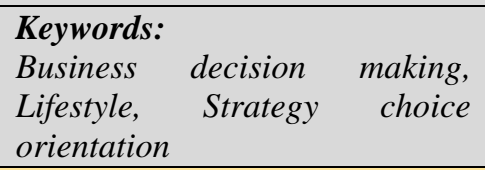 & \\
\hline I N F O A R T I K E L & A B S T R A K \\
\hline $\begin{array}{l}\text { Riwayat Artikel: } \\
\text { Diterima: } 9 \text { Juni } 2021 \\
\text { Direvisi: } 28 \text { Juli } 2021 \\
\text { Dipublikasikan: } 31 \text { Juli } 2021\end{array}$ & \multirow{2}{*}{$\begin{array}{l}\text { Penelitian ini bertujuan untuk membuktikan pengaruh gaya hidup, orientasi pilihan } \\
\text { strategi pada pengambilan keputusan usaha. Penelitian ini menggunakan data primer } \\
\text { melalui survei kepada pengusaha kuliner di kota Palembang. Data kuesioner yang } \\
\text { digunakan dalam penelitian ini adalah } 92(61,3 \%) \text {. Analisis Structural Equation } \\
\text { Modeling (SEM) Partial Least Squares (PLS) menggunakan perangkat lunak Warp } \\
\text { PLS versi 5.0 dipakai untuk menguji hipotesis penelitian. Hasil penelitian } \\
\text { menunjukkan bahwa gaya hidup orientasi pilihan strategi berpengaruh terhadap } \\
\text { pengambilan keputusan usaha. }\end{array}$} \\
\hline $\begin{array}{l}\text { Kata kunci: } \\
\text { Gaya hidup, Orientasi pili }\end{array}$ & \\
\hline
\end{tabular}

strategi, pengambilan keputusan usaha 


\section{PENDAHULUAN}

Pertumbuhan pelaku bisnis di kota Palembang saat ini telah berkembang dengan pesat. Bisnis tersebut banyak dijalankan dalam kategori UMKM kuliner. Berdasarkan data 2020, jumlah rumah makan/restoran di kota Palembang berjumlah 923 unit, hal ini meningkat 17,55\% dari data tahun 2018 sebanyak 761 unit (Badan Pusat Statistik, 2021). Pertumbuhan ini menunjukkan bahwa ada potensi ekonomi dari bisnis kuliner di kota Palembang. Selain itu, tumbuhnya bisnis kuliner tidak terlepas dari perkembangan gaya hidup masyarakat perkotaan. Hal ini seperti dijelaskan oleh Mufidah (2012) yang menyatakan bahwa perilaku konsumtif yang berkembang pada kelompok masyarakat di perkotaan tidak hanya didorong oleh kebutuhan tetapi juga didorong untuk menjaga gengsi dan gaya hidup. Untuk itu, perkembangan bisnis kuliner berkembang dihampir semua kota di Indonesia.

Keputusan sesorang untuk menjalankan sebuah bisnis muncul karena keinginannya untuk berwirausaha (Pramiswari dan Dharmadiaksa, 2017). Jiwa kewirausahaan mencakup karateritik yang berhubungan dengan keberanian dalam mengambil risiko, memiliki pemikiran tentang inovasi, kreativitas, agresivitas kompetitif, serta otonom atau bertindak secara independen, dan memiliki keahlian dalam mencari peluang (Zahra et al., 2019). Faktor yang memengaruhi keputusan seseorang untuk berwirausaha terdiri atas faktor internal seperti keingin bebas, menyukai tantangan dan faktor eksternal seperti kondisi ekonomi serta dukungan pihak luar (Irawati, 2017). Namun demikian, tumbuhnya jiwa kewirausahaan sesorang juga sering kali dipengaruhi oleh perkembangan manusia dalam menyikapi sebuah keadaan (Obschonka dan Silbereisen, 2012).

Berdasarkan informasi tersebut, bisnis kuliner telah menjadi pilihan bagi banyak orang untuk memperoleh penghasilan. Namun demikian, bisnis kuliner bukan saja bertujuan untuk memperolah penghasilan tetapi juga untuk menunjukkan posisi gensi seseorang. Oleh karena itu, bisnis kuliner juga sudah menjadi gaya hidup bagi banyak orang. Hal ini seperti dijelakan oleh Dawson et al. (2011) bahwa keputusan bisnis sering kali dipengaruhi oleh tujuan gaya hidup pemilik usaha. Boluk dan Mottiar (2014) juga menjelaskan bahwa keputusan seseorang menjalankan bisnis lebih banyak didasari oleh kepentingan sosial yang berhubungan dengan kepentingan untuk menunjukkan gaya hidup mereka. Dua literatur tesebut menunjukkan bahwa pilihan untuk menjalankan bisnis tidak sekedar berhubungan dengan aspek mendapatkan penghasilan, namun juga ada aspek gengsi dan gaya hidup yang akan menjadi pertimbangan. Gaya hidup berkembang mengikuti perubahan zaman dan modernitas (Sukmawati dan Ekasasi, 2020). Gaya hidup diyakini memiliki peranan penting dalam proses pengambilan keputusan seseorang 
termasuk di dalamnya adalah keputusan bisnis (Pangestu dan Suryoko, 2016). Pendapat lain menyatakan bahwa gaya hidup merupakan pola hidup seseorang di dunia yang diekspresikan dalam aktivitas, minat, dan opininya (Dewi dan Samuel, 2015).

Namun demikin, pengambilan keputusan bisnis juga akan bergantung pada orientasi pilihan strategi seseorang. Xiao et al. (2012) menjelaskan bahwa pengelolaan bisnis akan bergantung pada pilihan strategi yang relevan. Pilihan strategi kompetitif merupakan hal penting yang berperan dalam implementasi bisnis (Setiawan, 2020). Hal ini karena strategi yang tepat dapat melindungi investasi yang telah dilakukan seorang pengusaha (Xiao et al., 2012). Pendapat tersebut menunjukkan bahwa pilihan orientasi strategi merupakan faktor penting bagi seorang pengusaha untuk menentukan keputusan bisnis yang akan diambil. Hal ini bersalasan karena pilihan strategi yang tepat akan memberikan dampak pada tingkat keberhasilan yang akan diperoleh dalam sebuah proses bisnis (Setiawan, 2016).

Berdasarkan uraian di atas jelas bahwa perkembangan sebuah bisnis tidak terlepas dari motivasi seorang pengusaha dalam menjalankan usahanya, seperti motivasi gaya hidup atau gensi. Selain itu, orientasi strategi juga menjadi hal lain yang sering kali menjadi pertimbangan keputusan untuk menjalankan bisnis seseorang. Namun demikian, masih belum banyak hasil penelitian yang membahas pengaruh gaya hidup dan orientasi pilihan strategi sebagai faktor yang diidentifikasi sebagai pemicu keputusan seseorang menjalankan bisnis. Penelitian gaya hidup lebih banyak dilihat sebagai faktor dalam memutuskan membeli sebuah pruduk (Dewi dan Samuel (2015); Pangestu dan Suryoko (2016); Paendong dan Tielung (2016).

Pada sisi lain, penelitian tentang pilihan strategi lebih banyak dilakukan untuk melihat dampaknya pada kinerja. Penelitian semacam ini antara lain dilakukan oleh Adriana (2012); Hartini (2013); Kalkan (2014); Karabag et al (2014); Perwiranegara (2015); Turner et al. (2017); Setiawan et al. (2019); Setiawan dan Lina (2020); Setiawan et al. (2020a). Berdasarkan beberapa literatur yang berkembang tersebut, penelitian ini memiliki alasan yang kuat untuk melihat gaya hidup dan pilihan strategi pada keputusan sesorang untuk menjalankan bisnis kuliner di kota Palembang. Penelitian ini akan mejadi pembeda bahwa selama ini penelitian mengenai gaya hidup lebih dilihat sebagai faktor keputusan untuk membeli, dan pilihan strategi sebagia faktor untuk melihat pencapaian kinerja. 


\section{METODE PENELITIAN}

\section{Desain Penelitian}

Jenis penelitian dalam penelitian ini adalah metode kuantitatif menggunakan desain penelitian survei dengan melakukan pengujian hipotesis secara empiris. Unit analisis penelitian adalah pengusaha yang menjalankan bisnis kuliner melalui UMKM di kota Palembang. Survei dilakukan secara langsung kepada calon responden.

\section{Populasi dan Sampel}

Populasi dan sampel dalam penelitian ini adalah pelaku UMKM di kota Palembang yang menjalankan usaha kuliner. Populasi penelitian didasarkan pada jumlah usaha kuliner tahun 2020 yang dikeluarkan oleh BPS Kota Palembang yang menunjukkan jumlah rumah makan/restoran adalah sebanyak 923 unit. Teknik sampling pada penelitian ini menggunakan teknik nonprobability sampling convenience sample (Snowball Sampling). Teknik ini dipilih karena akan lebih memudahkan dalam mendapatkan sampel penelitian.

\section{Definisi Operasional}

Pada bagian ini dijelaskan variabel yang akan diteliti disertai indikator variabel yang digunakan. Variabel penelitian terdiri dari:

1. Variabel dependen: Pengambilan Keputusan Bisnis

Definisi pengambilan keputusan bisnis didasarkan pada Wijaya (2008) yang menyatakan bahwa keputusan bisnis seseorang akan tercermin pada sikap wirausaha yang dimilikinya, yaitu kecenderungan untuk bereaksi secara afektif dalam menanggapi risiko yang akan dihadapi dalam menjalankan bisnis. Indikator pengabilan keputusan bisnis menggunakan instrumen Wijaya (2008) yang sebelumnya telah dipakai oleh Gadaan (2008) yang diri dari ketertarikan pada peluang usaha, pandangan positif terhadap kegagalan usaha, dan keberanian menghadapi risiko usaha.

2. Varibel independen: Gaya Hidup dan Orientasi Strategi

Gaya hidup didefiisikan sebagai pola hidup seseorang di dunia yang diekspresikan dalam aktivitas, minat, dan opininya, yang dicerminkan melalui identitas dirinya lewat penggunaan waktu, uang dan barang. (Dewi dan Samuel, 2015).

Orientasi strategi didefinisikan sebagai pilihan seseorang untuk lebih mendorong pemberdayaan partisipatif, berorientasi jangka panjang dan fokus pada kreativitas dan inovasi (Setiawan et al., 2020b) 


\section{Teknik Pengumpulan Data}

Jenis data yang akan dipakai dalam penelitian ini adalah data primer. Data dikumpulkan menggunakan metode survei dengan alat bantu berupa instrumen kuesioner. Data penelitan berupa tingkat kesetujuan responden terhadap item-item indikator setiap variabel penelitian.

\section{Teknik Analisis Data}

\section{Statistik Deskriptif}

Penggunaan statistik deskriptif adalah untuk memberikan deskripsi mengenai variabelvariabel penelitian.

\section{Uji Kualitas Data}

Data penelitian ini dikumpulkan melalui survei dengan menggunakan kuesioner. Variabel penelitian ini diukur menggunakan metode pengukuran konstruk reflektif. Hair et al. (2013) mensyaratkan pengujian model pengukuran reflektif didasarkan pada nilai composite reliability sebesar $>0,7$, convergent validity (average variance extracted) sebesar $>0,5$, indicator reliability (loading) sebesar > 0,7. Pengujian terakhir untuk menilai validitas dan reliabilitas adalah pengujian validitas diskriminan. Pengujian validitas diskriminan bisa dilakukan dengan cara membandingkan akar kuadrat AVE terhadap nilai korelasi antar konstruk. Akar kuadrat dari setiap AVE konstruk harus lebih besar dari korelasi tertinggi konstruk lainnya.

\section{Pengujian Hipotesis}

Pengujian hipotesis dilakukan menggunakan analisis Structural Equation Modeling (SEM) Partial Least Squares (PLS). Analisis SEM-PLS menggunakan software Warp PLS versi 5.0. Dua tahapan dalam pengujian PLS dapat dijelaskan sebagai berikut:

1) Pengujian kualitas model

Pengujian kulitas model SEM-PLS didasarkan pada model fit dan quality indices yang terdiri dari tiga indikator fit yaitu average path coefficient (APC), average R-square (ARS), dan average variance inflation factor (AVIF). Kriteria p-value untuk APC dan ARS adalah harus lebih kecil dari 0,05. Sementara, AVIF sebagai indikator multikolinieritas harus memiliki nilai lebih kecil dari 5 (Kock. 2011) 
2) Pengujian hipotesis penelitian.

Pengujian hipotesis didasarkan pada nilai path coefficients $\beta$ dan signifikansi $p$-values. Untuk menguji hipotesis berarah negatif maka nilai path coefficients $\beta$ harus bernilai negatif dengan signifikansi $p$-values di bawah $\alpha$ 5\%. Sebaliknya, hipotesis berarah positif diuji dengan melihat nilai path coefficients $\beta$ harus bernilai positif dengan signifikansi $p$-values di bawah $\alpha 5 \%$.

\section{HASIL DAN PEMBAHASAN}

Pengumpulan data dilakukan pada kurun waktu kurang lebih 3 minggu mulai minggu pertama Maret 2021 hingga minggu ketiga Maret 2021. Tabel 1 menunjukkan jumlah penyebaran kuesioner penelitian. Survei dilakukan kepada pengusaha yang menjalankan bisnis kuliner melalui UMKM di kota Palembang. Sejumlah 150 kuesioner telah disampaikaan kepada responden, namun kuesioner yang kembali dan dapat dianalisis dalam proses pengolahan data sebanyak 92 kuesioner atau dengan tingkat respon sebesar $61,3 \%$. Sebanyak 58 kuesioner lainya tidak kembali dengan berbagai alasan dan tidak dapat diproses dalam pengolahan data penelitian.

Tabel 1. Hasil Pengembalian Koesioner

\begin{tabular}{ll}
\hline \multicolumn{1}{c}{ Keterangan } & \multicolumn{1}{c}{$\begin{array}{c}\text { Jumlah } \\
\text { kuesioner }\end{array}$} \\
\hline Jumlah kuesioner survei yang disampaikan kepada responden & 150 \\
Jumlah kuesioner yang tidak direspon & 58 \\
Jumlah kuesioner yang respon dan dianalisis & 92 \\
Tingkat respon & $61,3 \%$ \\
\hline
\end{tabular}

Sumber: Data diolah

Tabel 2. Profil Responden

\begin{tabular}{llll}
\hline \multicolumn{1}{c}{ Profil Responden } & \multicolumn{1}{c}{ Jumlah } & Persentase (\%) & \\
\hline Jenis Kelamin & & & \\
Perempuan & 34 & $37 \%$ & \\
Laki-laki & 58 & $63 \%$ & \\
& & & Rata-rata \\
\cline { 2 - 4 } & Termuda/Terbaru & Tertua/Terlama & 44 \\
Usia & 18 & 58 & 4 \\
Lama Usaha & 1 & 12 & \\
\hline
\end{tabular}

Sumber: Data diolah

Tabel 2 menunjukkan profil responden penelitian. Responden yng berpartisipasi dalam penelitian ini berjumlah 92 responden. Reeponden terbanyak berjenis laki-laki, yaitu sebanyak 58 orang atau 63\%, sementara, responden perempuan berjumlah 34 orang atau 34\%. Data ini menunjukkan bahwa pengelolan bisnis kuliner di kota Palembang masih didominasi oleh kaum laki-laki. Usia responden berkisar pada usia antara 18 samapi 58 tahun dengan rata-rata usia adalah 
44 tahun. Hal ini menunjukkan bahwa banyak pengusaha kuliner di kota Palembang berada pada usia produktif. Lama usaha rata-rata adalah 4 tahun, dengan usaha terbaru adalah 1 tahun dan terlama 12 tahun. Hal ini menunjukkan bahwa banyak usaha kuliner yang masih relatif baru dan menunjukkan bahwa saat ini sedang menjadi trend adanya bisnis usaha kuliner.

Tabel 3. Data Penelitian

\begin{tabular}{llccl}
\hline \multicolumn{1}{c}{ Variabel } & $\begin{array}{c}\text { Kisaran } \\
\text { Teoritis }\end{array}$ & $\begin{array}{c}\text { Kisaran } \\
\text { Aktual }\end{array}$ & Mean & $\begin{array}{c}\text { Standar } \\
\text { Deviasi }\end{array}$ \\
\hline Pengambilan Keputusan Usaha & $3-18$ & $6-15$ & 12,98 & 2,77 \\
Gaya Hidup & $3-18$ & $5-18$ & 12,19 & 2,71 \\
Orientasi Pilihan Strategi & $3-18$ & $5-18$ & 12,12 & 2,74 \\
\hline
\end{tabular}

Sumber: Data diolah

Tabel 3 merupakan data pengambilan keputusan usaha yang dilakukan oleh para pengusaha kuliner di kota Palembang berada pada nilai rata-rata 12,98 dengan kisaran teoritis antara 3 - 18 dan kisaran aktual antara $6-15$. Hal ini menunjukkan bahwa tingkat pengambilan keputusan usaha yang dilakukan oleh para pengusaha kuliner di kota Palembang cenderung memiliki tingkat yang relatif cukup tinggi. Data gaya hidup para pengusaha kuliner di kota Palembang berada pada nilai rata-rata 12,19 dengan kisaran teoritis antara 3 - 18 dan kisaran aktual antara 5 - 18. Hal ini juga menunjukkan bahwa tingkat gaya hidup para pengusaha kuliner di kota Palembang cenderung memiliki tingkat yang relatif cukup tinggi. Akhirnya, data orientasi pilihan strategi para pengusaha kuliner di kota Palembang berada pada nilai rata-rata 12,12 dengan kisaran teoritis antara 3 - 18 dan kisaran aktual antara 5 -18. Hal ini juga menunjukkan bahwa tingkat orientasi pilihan strategi para pengusaha kuliner di kota Palembang cenderung memiliki tingkat yang juga relatif cukup tinggi. hal ini berarti bahwa para pengusaha kuliner di kota Palembang cenderung untuk mengedepankan partisipasi, berpikir jangka panjang dan ingin inovasi dan kreatif.

Tabel 4. Hasil Pengujian Validitas dan Reliabilitas Data

\begin{tabular}{llll}
\hline \multicolumn{1}{c}{ Variabel Penelitian } & Loading & Composite Reliability & AVE \\
\hline Pengambilan Keputusan Usaha & & & 0,892 \\
PKU1 & 0,790 & 0,961 & \\
PKU2 & 0,777 & & \\
PKU3 & 0,791 & & 0,787 \\
Gaya Hidup & & & \\
GH1 & 0,741 & 0,879 & \\
GH2 & 0,781 & & 0,741 \\
GH3 & 0,705 & & \\
Orientasi Pilihan Strategi & & & \\
OPS1 & 0,779 & 0,890 & \\
OPS2 & 0,731 & & \\
OPS3 & 0,772 & & \\
\hline Sum & & &
\end{tabular}

Sumber: Data diolah 
Tabel 4 menunjukkan hasil validitas dan reliabilitas data penelitian. Hasil pengujian menunjukkan nilai composite reliability setiap konstruk $>0,7$. Begitupun dengan nilai convergent validity (average variance extracted) setiap kontruk berada pada nilai $>0,5$. Untuk nilai indicator reliability (loading) semua konstruk $>0,7$. Oleh karena itu, semua indikator kontruk penelitian dapat dipakai.

Tabel 5 menunjukkan hasil pengujian validitas diskriminan atas pengukuran instrumen konstruk penelitian. Hasil pengujian pada Tabel 5 menunjukkan nilai akar kuadrat AVE setiap konstruk lebih besar dari korelasi tertinggi konstruk lainnya. Berdasarkan dua hasil pengujian yang ditunjukkan pada Tabel 4 dan 5 dapat disimpulkan bahwa pengukuran konstrak dalam model penelitian ini adalah valid dan reliabel.

Tabel 5. Validitas Diskriminan Data Penelitian

\begin{tabular}{clll}
\hline \multicolumn{1}{c}{ PKU } & \multicolumn{1}{c}{ GH } & OPS \\
\hline PKU & 0,944 & & \\
GH & $0,586^{* * *}$ & 0,841 & \\
OPS & $0,524^{* * *}$ & $0,673^{* * *}$ & 0,861 \\
\hline
\end{tabular}

Elemen diagonal: akar kuadrat dari AVE, elemen off-diagonal: korelasi antar konstruk $* * *$ signifikan pada $p<0,01 \quad * *$ signifikan pada $p<0,05$

Tabel 6 menunjukkan model fit dan quality indices nilai APC, ARS dan AVIF. Nilai signifikansi APC $<0,001$, nilai ARS $<0,001$ berada pada kriteria di bawah 5\% (Kock, 2011). Begitupun dengan nilai AVIF sebesar 1,086 berada pada kriteria di bawah angka 5 (Kock, 2011). Berdasarkan hasil pengujian tersebut, model penelitian adalah fit sehingga layak untuk dilanjutkan pada pengujian hipotesis.

Tabel 6. Model Fit dan Quality Indices

\begin{tabular}{llll}
\hline \multicolumn{1}{c}{ Item Model Fit } & \multicolumn{1}{c}{ Nilai } & \multicolumn{1}{c}{ Kriteria } & \multicolumn{1}{c}{ Kesimpulan } \\
\hline Average path coefficient (APC) & $0,384(\mathrm{P}<0,001)$ & $\mathrm{P}<0,05$ & Sesuai \\
Average R-squared (ARS) & $0,511(\mathrm{P}<0,001)$ & $\mathrm{P}<0,05$ & Sesuai \\
Average block VIF (AVIF) & 1,739 & $\mathrm{AVIF}<5$ & Sesuai \\
\hline
\end{tabular}

Sumber: Data primer diolah 


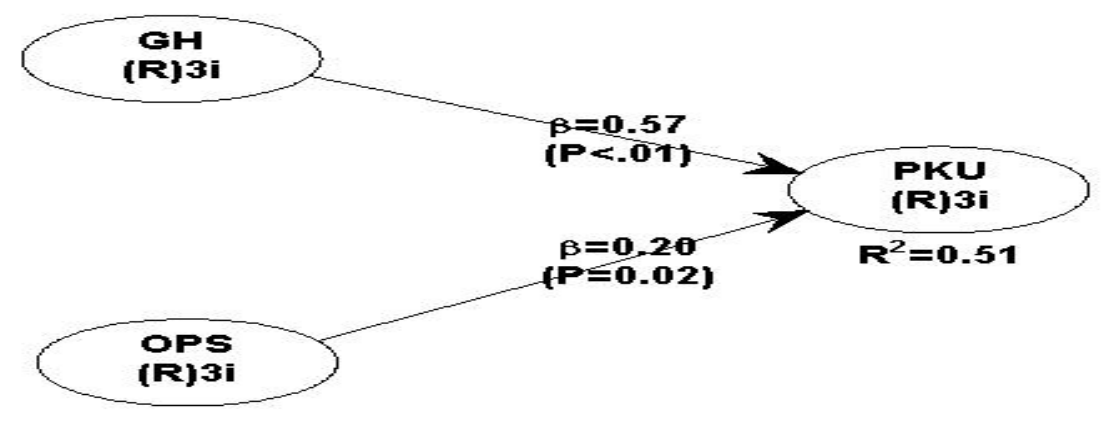

Gambar 1. Struktur Model Penelitian

Gambar 1 dapat dilihat bahwa variabel gaya hidup memiliki nilai koefisien $\beta$ sebesar 0,57 dengan nilai $\mathrm{p}<0,01$ atau berada pada nilai $\alpha 1 \%$ terhadap variabel pengambilan keputusan usaha. Hal ini membuktikan bahwa terdapat pengaruh positif antara gaya hidup pengusaha UMKM kuliner di kota Palembang terhadap pengambilan keputusan usaha mereka. Temuan ini mengkonfirmasi bahwa keputusan membangun usaha kuliner tidak terlepas dari gengsi dan gaya hidup pemilik. Seorang pengusaha yang memiliki cafe atau restoran akan merasa mengikuti gaya masa kini. Cafe atau restoran merupakan tempat berkumpulnya anak muda atau para sosialita. Anak muda atau para sosialita yang hobby berkumpul di sebuag cafe atau restoran sering kali juga ingin menunjukkan eksistensi gaya hidup mereka. Oleh sebab itu, keputusan seorang pengusaha untuk membangun usaha kuliner juga menunjukkan bagaiman eksistensi mereka untuk mengaktualisasikan gaya hidup dan gensi mereka. Temuan ini mendukung Dawson et al. (2011) yang menyakatan bahwa pengambilan keputusan kuliner tidak terlepas dari gaya hidup pemilik usaha. Pendapat ini juga didukung oleh Boluk dan Mottiar (2014) bahwa keputusan seseorang menjalankan bisnis lebih banyak didasari kepentingan untuk menunjukkan gaya hidup mereka.

Gambar 1 juga menunjukkan hasil pengujian pengaruh variabel orientasi pilihan strategi pada variabel pengambilan keputusan usaha. Variabel orientasi pilihan strategi memiliki nilai koefisien $\beta$ sebesar 0,20 dengan nilai p 0,02 atau berada pada nilai $\alpha$ 5\% terhadap variabel pengambilan keputusan usaha. Hal ini membuktikan bahwa terdapat pengaruh positif antara orientasi pilihan strategis pengusaha UMKM kuliner di kota Palembang terhadap pengambilan keputusan usaha mereka. Temuan ini mengkonfirmasi bahawa sebuah keputusan bisnis akan sangat bergantung pada pilihan strategi seorang pengusaha. Pada tingkat persaingan yang dinamis, hal ini dibuktikan dengan pertumbuhan yang pesat dalam industri kuliner di kota Palembang, masih banyak pengusaha yang tertarik membuka usaha kuliner. 
Hal ini didukung oleh data empiris penelitian yang menunjukkan bahwa mayoritas pengusaha kuliner di kota Palembang lebih memilih strategi yang berbasis pada mengedepankan partisipatif, melihat tujuan jangka panjang, inovatif dan kreatif. Hal ini relevan dengan keberanian mereka dalam membuat keputusan untuk menjalankan usaha kuliner. Oleh karena itu, temuan penelitian ini mendukung temuan terdahulu Xiao et al. (2012) bahwa pengambilan keputusan suatu bisnis akan bergantung pada orientasi pilihan strategi yang dimiliki oleh seorang. pengusaha menjelaskan bahwa pengelolaan bisnis akan bergantung pada pilihan strategi yang relevan. Hal ini disukung oleh temuan Setiawan (2020) bahwa pilihan strategi kompetitif merupakan hal penting yang berperan dalam mengimplementasikan sebuah bisnis baru.

\section{KESIMPULAN}

Temuan penelitian ini menyimpulkan bahwa pengambilan keputusan usaha yang dilakukan oleh pengusaha UMKM kuliner di kota Palembang dipengaruhi oleh faktor gaya hidup dan orientasi pilihan strategi mereka. Hasil penelitian ini memberikan implikasi penting bagi calon pengusaha yang akan membangun usaha kuliner diberbagai tempat. Usaha kuliner yang berkembang pesat akan berhadapan dengan persaingan yang dinamis. Oleh karena itu, pengusaha kuliner harus melihat gaya hidup sebagai pertimbangan dalam membangun usaha kuliner mereka. Hal ini dikarenakan para konsumen cafe atau restoran juga banyak yang menggunakan gaya hidup untuk berkunjung dan menikmakti layanan bisnis kuliner. Pengusaha kuliner juga harus memastikan orientasi pilihan strategi mereka. Hal ini karena persangan bisnis kuliner yang dinamis harus didukung oleh orientasi strategi yang kompetitif dan mampu beradaptasi dengan tuntutan kebutuhan pelanggan.

Akhirnya, hasil penelitian ini juga masih memiliki beberapa keterbatasan, antara lain belum melihat karakteristik pengusaha kuliner dalam kategori etnis, usia, dan strata sosial. Penelitian akan memberikan perspektif yang berbeda dan menarik jik tiga kategori karakteristik tersebut dilihat. Perbedaan etnisitas pengusaha akan dapat menunjukkan kebiasan bisnis mereka berdasarkan nilainilai etnisitasnya, usia dapat menunjukkan orientasi pasar yang mereka tuju, sedangan strata sosial akan lebih menunjukkan tingkat gengsi atau gaya hidup yang berbeda. Untuk itu, saran untuk penelitian kedepan supaya dapat mempertimbangan tiga karakteristik tersebut untuk melengkapi hasil penelitian ini. 


\section{DAFTAR PUSTAKA}

Adriana, M. 2012. Pengaruh inovasi dan pemberdayaan terhadap kinerja manajerial dengan anggaran sebagai variabel moderating. Jurnal Maksi. Vol. 12 (1). pp. 139 - 155.

Boluk, Karla dan Ziene Mottiar. (2014). Motivations of social entrepreneur: Blurring the social Contribution and Profits Dichotomy. Social Enterprise Journal Vol 10 (1). pp 53 - 68.

Badan Pusat Statistik. (2021). Palembang dalam angka 2021. BPS Palembang: Palembang

Dawson, D. Fountain, J dan Cohen. D. A. (2011). Seasonality and the lifestyle "Conundrum": An analysis of lifestyle entrepreneurship in wine tourism regions, Asia Pacific Journal of Tourism Research Vol.16 (5). pp. 551 - 572.

Dewi, M. N. dan Samuel, H. (2015). Pengaruh gaya hidup (lifestyle), harga, promosi terhadap pemilihan tempat tujuan wisata (destination) studi kasus pada konsumen Artojaya Tour \& Travel Surabaya. Jurnal Manajamen Pemasaran Petra. Vol. 3 (1). pp. 1 - 13.

Gaddam, S. (2008). Identifying the relayionship between behavioral motives and entrepreneurial intentions: An empirical study based participations of business management students. The Icfaian Journal of Management Research. Vol. 7. pp. 35 - 45

Hair, J. F. Hult, G. T. M. Ringle, C. M. dan Sartsedt, M. 2013. A prime on partial least squares stuctural equation modeling (PLS-SEM). Los Angeles: Sage.

Hartini, S. 2013. Hubungan orientasi pasar, strategi bersaing, kewirausahaan korporasi dan kinerja perusahaan. EKUITAS Jurnal Ekonomi dan Keuangan. Vol. 17 (1). pp. 39 - 53.

Irawati, R. (2017). Pengambilan keputusan usaha mandiri mahasiswa ditinjau dari faktor internal dan eksternal. Jurnal JIBEKA. Vol. 11(1). pp. $58-69$.

Kalkan, A. Bozkurt, O. C. dan Arman, M. 2014. The Impacts of intellectual capital, innovation and organizational strategy on firm performance. Procedia - Social and Behavioral Science. Vol. 150 (September). pp. $700-707$.

Karabag, S. F. dan Berggren, C. 2014. Antecedents of firm performance in emerging economies: Business groups, strategy, industry structure, and state support. Journal of Business Research. Vol. 67 (10). pp. $2212-2223$.

Kock, N. 2011. Using WrapPLS in e-collaboration studies: Descriptive statistics, settings, and key analysis results. International Journal of e-Collaboration. Vol. 7 (2). pp. 1 - 18.

Mufidah, N. L. (2012). Pola konsumsi Masyarakat Perkotaan: Studi Deskriptif Pemanfaatan foodcourt oleh keluarga. BioKultur. Vol. 1(2). pp. $157-178$.

Obschonka, M. dan Silbereisen, R. K. (2012). Entrepreneurship from a developmental science perspective. International Journal of Developmental Sciences. Vol 6(3-4). Vol. 107 - 115.

Paendong, M. dan Tielung, M. V. J. (2016). Pengaruh kebutuhan dan gaya hidup terhadap pembelian ponsel smartfren di galeri smartfren cabang Manado. Jurnal Berkala Ilmiah Efisiensi. Vol. 16 (4). pp. $122-130$. 
Pangestu, S. D. dan Suryoko, S. (2016). Pengaruh gaya hidup (life style) dan harga terhadap keputusan pembelian (Studi kasus pada pelanggan Peacockoffie Semarang). Jurnal Administrasi Bisnis. Vol 5 (1). pp. $63-70$.

Perwiranegara, A. H. 2015. Pengaruh orientasi kepemimpinan pasar dan strategi inovasi terhadap kinerja UKM. Jurnal Aplikasi Manajemen. Vol. 13 (1). pp. 77 - 89.

Pramiswari, D. A Y. dan Dharmadiaksa, I. B. (2017). Pengaruh e-commerce dan penggunaan sistem informasi akuntansi dalam pengambilan keputusan untuk berwirausaha studi kasus mahasiswa program studi akuntansi Universitas Udayana. E-Jurnal Akuntansi. Vol 20 (1). pp. $261-289$.

Setiawan, A. S (2016). Pengaruh pemilihan strategi deferensiasi terhadap kinerja keuangan (Studi empiris pada perusahaan manufaktur food \& beverages terdaftar di BEI). Jurnal Akuntansi. Vol 20 (1). pp. $104-116$.

Setiawan, A. S. Rahmawati. Djuminah. Dan Widagdo, A. K (2019). Owner power, deliberate strategy formulation, and strategic management accounting. Opcion. Vol 35 (89). pp. 254 270.

Setiawan, A. S (2020). Orientasi pasar, pilihan strategi dan peran fungsional akuntansi: Studi pada industri hotel di Sumatera Selatan. Journal of Business and Information Systems, Vol. 2 (1). pp. $1-11$.

Setiawan, A.S. dan Lina. (2020). Keputusan afiliasi OTA dan kinerja Hotel (Studi pada hotel berafiliasi). Journal of Business and Information Systems. Vol. 2 (2). pp. 106 - 112.

Setiawan, A.S. Lina. dan Widyartono, A. (2020). The impact of novelty and meaningfulness creative marketing program on hotel performance. Jurnal Manajemen. Vol. 24 (3). pp. 342 357.

Setiawan, A.S. Ony, J. G. dan Permata, V. S. (2020). The effect of cultural values on business strategy choices. Jurnal Manajemen. Vol. 24 (1). pp. 158 - 173.

Sukmawati, N. dan Ekasasi. S. R. (2020). Pengaruh gaya hidup, kualitas produk, dan promosi terhadap keputusan pembelian produk makanan sehat Soyjoy. CAKRAWANGSA BISNIS. Vol. 1 (1). pp. $17-27$.

Turner, M. J. Way, S. A. Hodari, D. dan Witteman, W. 2017. Hotel property performance: The role of strategic management accounting. International Journal of Hospitality Management. Vol. 63 (1). pp. 33-43.

Wijaya, T. (2008). Kajian model empiris perilaku berwirausaha UKM DIY dan Jawa Tengah. Jurnal Manajemen dan Kewirausahaan. Vol. 10 (2). pp. 93 - 104.

Xiao, Q. O'Neill, J. W. dan Mattila, A.S. 2012. The role of hotel owners: The influence of corporate strategies on hotel performance. International Journal of Contemporary Hospitality Management. Vol. 24 (1) pp. 122 - 139.

Zahra, A. A. Husna, A. N. dan Haq, A. L. A. (2019). Dinamika pengambilan keputusan dan perkembangan jiwa wirausaha pada mahasiswa. PSYMPATHIC: Jurnal Ilmiah Psikologi. Vol. 6 (1). pp. $113-130$. 